\title{
TerraSAR-X high-resolution radar remote sensing: an operational warning system for Rift Valley fever risk
}

\author{
Cécile Vignolles $^{1}$, Yves M. Tourre ${ }^{2,3}$, Oscar Mora ${ }^{4}$, Laurent Imanache ${ }^{1}$, Murielle Lafaye ${ }^{1}$ \\ ${ }^{1}$ Centre National d'Etudes Spatiales (CNES), 18 Avenue Edouard Belin, 31401 Toulouse Cedex 9, France; \\ ${ }^{2}$ Météo-France, 42 Avenue Coriolis, 31057 Toulouse Cedex 1, France; ${ }^{3}$ Lamont Doherty Earth \\ Observatory (LDEO), Columbia University, Palisades, NY 10964, USA; ${ }^{4}$ ALTAMIRA Information, Parc \\ Technologique du Canal, 10, Avenue de l'Europe, 31520 Ramonville Saint Agne, France
}

\begin{abstract}
In the vicinity of the Barkedji village (in the Ferlo region of Senegal), the abundance and aggressiveness of the vector mosquitoes for Rift Valley fever (RVF) are strongly linked to rainfall events and associated ponds dynamics. Initially, these results were obtained from spectral analysis of high-resolution $(\sim 10 \mathrm{~m})$ Spot-5 images, but, as a part of the French AdaptFVR project, identification of the free water dynamics within ponds was made with the new high-resolution (down to 3-meter pixels), Synthetic Aperture Radar satellite (TerraSAR-X) produced by Infoterra GmbH, Friedrichshafen/Potsdam, Germany. During summer 2008, within a 30 x $50 \mathrm{~km}$ radar image, it was found that identified free water fell well within the footprints of ponds localized by optical data (i.e. Spot-5 images), which increased the confidence in this new and complementary remote sensing technique. Moreover, by using near real-time rainfall data from the Tropical Rainfall Measuring Mission (TRMM), NASA/JAXA joint mission, the filling-up and flushingout rates of the ponds can be accurately determined. The latter allows for a precise, spatio-temporal mapping of the zones potentially occupied by mosquitoes capable of revealing the variability of pond surfaces. The risk for RVF infection of gathered bovines and small ruminants $\left(\sim 1\right.$ park $\left./ \mathrm{km}^{2}\right)$ can thus be assessed. This new operational approach (which is independent of weather conditions) is an important development in the mapping of risk components (i.e. hazards plus vulnerability) related to RVF transmission during the summer monsoon, thus contributing to a RVF early warning system.
\end{abstract}

Keywords: Rift Valley fever, mosquitoes, TerraSAR-X, high-resolution remote sensing, early warning systems, Senegal.

\section{Introduction}

Rift Valley fever (RVF) is one of the most significant zoonoses in Senegal capable of causing major epidemics among livestock and humans (Bouloy and Weber, 2008). Indeed, RVF is highly contagious for humans if animals are viraemic at the time of slaughter. However, one of RVF's greatest impacts is upon trade. After epizootics, livestock trades may be

Corresponding author:

Yves M. Tourre

Météo-France

42 Avenue Coriolis

31057 Toulouse Cedex 01, France

Tel. +3305 6107 8149; Fax +3305 61078147

E-mail: yves.tourre@meteo.fr; yvestourre@aol.com banned for several years, severely affecting the livelihood of pastoralists. In the pastoral regions of the Ferlo, since incomes are almost entirely derived from the sale of mature cattle and ruminants, any perturbation of this trade will have disastrous effects on highly vulnerable populations and pastoral groups. RVF early warning system (RVFews) should mitigate those effects.

The conceptual approach of tele-epidemiology has been successfully tested through emerging RVF in the Ferlo region of Senegal. The region became prone to RVF in the late 1980s from the rapid appearance of the RVF mosquito vectors Aedes vexans and Culex poicilipes (Bâ et al., 2005; Lacaux et al., 2007). These vectors were found to proliferate in the vicinity of temporary ponds and neighbouring humid 
vegetation during the summer monsoon. RVF epizootic outbreaks in livestock may cause spontaneous mortality seriously impacting local socio-economic resources (Bâ et al., 2006). In the Ferlo, teleepidemiology has furthered an understanding of potential risk zones characterised by hazards and host vulnerability, where populations and cattle are exposed to the RVF virus (Vignolles et al., 2009). The ultimate goal in the above studies was thus to detect the smallest ponds (breeding sites) from space using Spot-5 images and derived products and to estimate areas under potential RVF threat. Risks were characterised and ranked within zones potentially occupied by mosquitoes (ZPOMs). To get to this level of detailed information, key parameters and confounding factors were identified:

(i) meteorological (spatio-temporal rainfall variability and distribution);

(ii) entomological (flying-range, aggressiveness and embryogenesis of vectors); (iii) environmental (hydrology and ponds limnology); and

(iv) pastoral (statistics regarding animals gathered together).

ZPOMs were derived from clustered ponds identified from space, and their dynamics (filling-up and flushing-out) after a so-called "productive rainfall" event (more than $10 \mathrm{~mm}$ ) in terms of Ae. vexans presence and aggressiveness.

The near real-time monitoring of the water bodies (i.e. ponds clustered or not) has become a prerequisite for prevention of RVF epidemics. In the vicinity of the Barkedji village (within the black square in Fig. 1) the mosquitoes thrive in areas where numerous ponds and humid zones offer favourable conditions for egg laying and hatching. Geo-referencing of all water bodies and their extensions and distribution have been accomplished in the Ferlo region using Spot-5 images and derived products. In order to become opera-

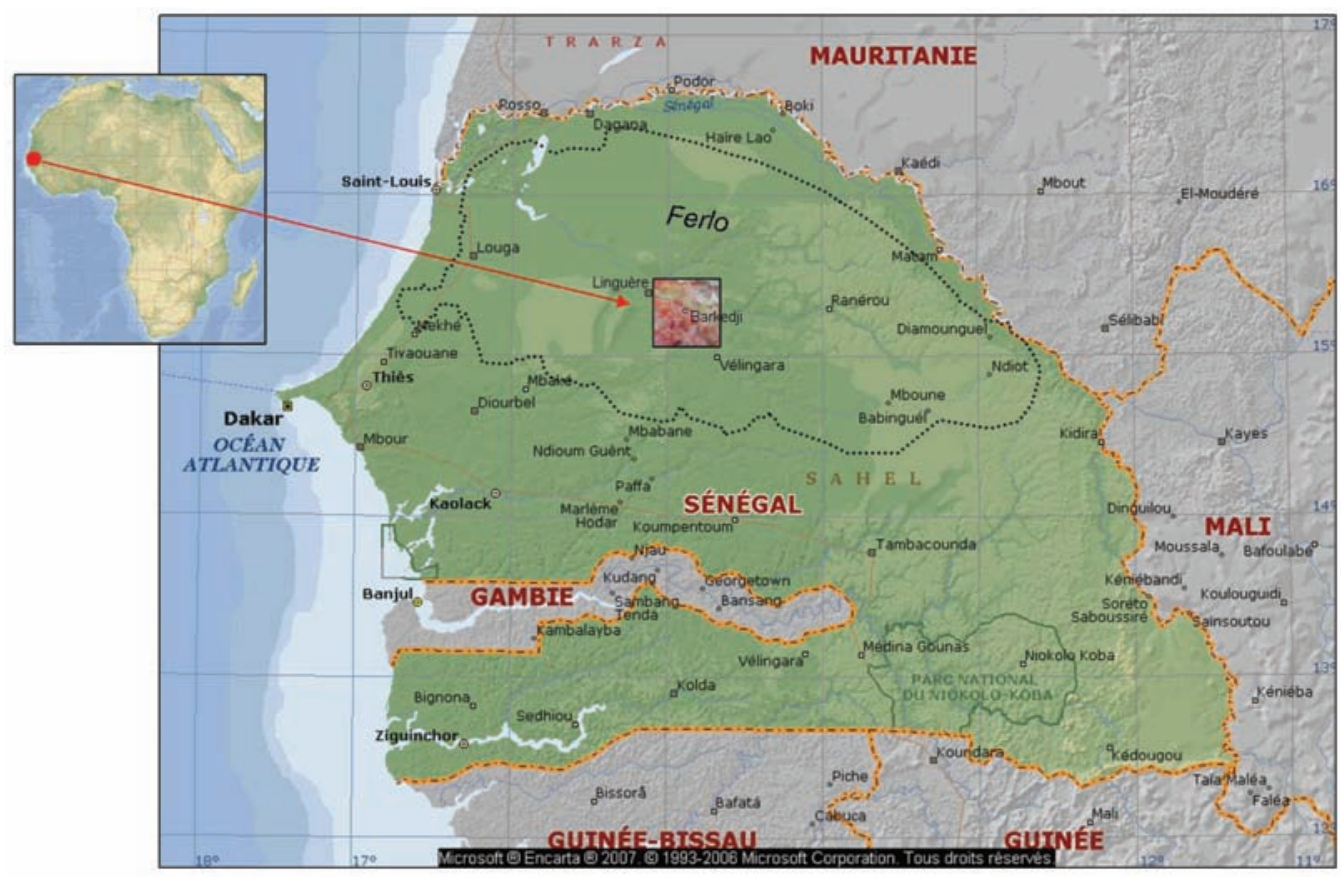

Fig. 1. Map of Senegal (West Africa) from Encarta ${ }^{\circledR} 2007$ (C) 1993-2006 Microsoft ${ }^{\circ}$ Corporation. The black dotted line marks the Ferlo eco-geographic zone. The small black square with $40 \mathrm{~km}$ side, outlines the study area within the Ferlo region of Senegal and surrounds the Barkedji village. 
tional in terms of ZPOMs, spatio-temporal variability during the summer monsoon, pond dynamics and humid areas must be accomplished for all weather conditions. As a part of the AdaptFVR project, this new research demonstrates the feasibility of using radar data and interferometry techniques for operational purposes. The advantage of interferometry has been demonstrated for delineation and density mapping of forested areas and delineation of surface water extent under adverse weather conditions such as monsoon rainfall. We used imaging microwave radar onboard the German Aerospace Center (DLR) satellite, which was launched in July 2007. Its helio-synchronous orbits with X-band, Synthetic Aperture Radar (SAR) of $9.65 \mathrm{GHz}, 300 \mathrm{MHz}$ bandwidth with 4polarization modes and repeat cycles of 11 days allows processing of resolution images on different swath widths. If these new results agree with those obtained from Spot-5 during clear atmospheric conditions, this new tele-epidemiological approach will be integrated into the RVFews as described by Tourre et al. (2008).

Climate and environment vary across many spatio-temporal scales, including climate change, impacting ecosystems, vector-borne diseases and public health worldwide. The objective of this project was to contribute to the implementation of operational early warning systems for RVF based on both natural and anthropogenic climatic and environmental changes. A conceptual approach by mapping climatic and environmental conditions from space and studying their linkages with RVF epidemics in Senegal was first developed. This approach, using precise remote sensing techniques, relies upon rainfall distribution which can be evaluated from space. Our research is part of the newly funded (2008) AdaptFVR project, facilitated by the "Gestion des Impacts du Changement Climatique (GICC)", a programme supported by the French "Ministère de l'Ecologie, de l'Energie, du Développement durable et de la Mer (MEEDM)" (see http://www.gip-ecofor.org /gicc/).

\section{Materials and methods}

High-resolution radar imagery based on TerraSAR$X$ data

Six TerraSAR-X images were used in "strip-map mode" during the summer monsoon season of 2008 (from 27 July to 1 October). SAR systems operate independently of the weather (i.e. through cloud cover) with a spatial resolution of $3 \mathrm{~m}$. Radar images of $30 \mathrm{~km}$ (zonally) x $50 \mathrm{~km}$ (meridionally) were produced from the Barkedji area. Interferometric SAR (InSAR) data are used for the detection of free water, whilst additional, polarimetric data reveal the humid zones. An interferogram and algorithms developed by Altamira (Altamira Information, 2008) were used. Interferometric coherence is always low for unstable surfaces like water surfaces. Nevertheless, interferometric coherence is a parameter that provides valuable information completely different from that of SAR backscatter.

InSAR quality from the interferogram is affected by many factors such as Döppler centroid differences, length of baselines and atmospheric effects, among others. It can be estimated through the data coherence technique. Indeed, coherence between several images can be used to discriminate areas with presence of free water. It is recognised that coherence estimation is often biased making it essential to apply an asymptotically unbiased coherence estimation method. This is accomplished using the coherence computation method from a digital elevation model (DEM) (see Zhang and Prinet, 2004).

Taking into account (i) the changes in reflectivity when quiescent water is compared with that of neighbouring surfaces; (ii) the low InSAR coherence when two different images obtained from a short temporal baseline are composited; and (iii) the high spatial resolution for the detection of small water bodies, four steps were used to detect free-water bodies (see also Fig. 2). The first step generates three different images. First, a coherence map is obtained 
by combining two different but almost contemporaneous images that together produce an interferogram. Coherence is high where terrain characteristics do not change and low where they do. Water bodies, due to specular reflection (mirror-like reflection of light; see Phong, 1975), present very low coherence. To obtain a coherence map, multi-look processing is mandatory. As this latter approach might degrade spatial resolution to some extent, two images are produced:

(i) a low-resolution reflectivity image through the multi-look processing which reduces the original spatial resolution; and

(ii) a high-resolution reflectivity image with its associated amplitude radiometric response image and original spatial resolution.

The second step uses two decision-making trees obtained for the generation of two masks which

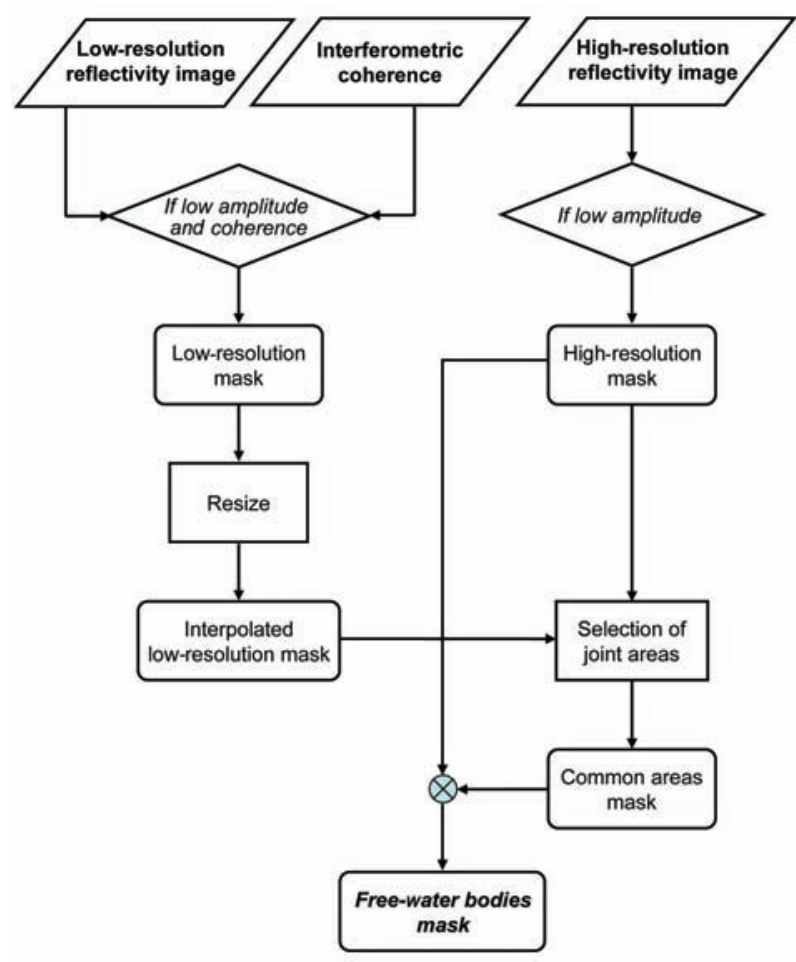

Fig. 2. Methodology and decision making trees for generation of free-water bodies masks, using SAR remote sensing technique. The inclusion of interferometric coherence with lowresolution reflectivity image is displayed (to the left). contain water bodies at both low and high spatial resolutions. Amplitude and coherence are used to create a low-resolution mask. This mask is a good proxy since amplitude and coherence criteria are involved in the decision-making trees. Nevertheless, the resolution is not good enough. If a high-resolution mask is computed using only image reflectivity (i.e. not its coherence), resolution is preserved but detection is degraded. A compromise has to be considered which leads to the third step, which consists in comparing both low- and high-resolution masks and identifying their common areas. This results in a mask which contains relatively coarse information about the spatial location of the water bodies.

The fourth step, finally, combines high-resolution and joint-areas masks to produce the "final water body" mask. This can be easily accomplished since detailed water areas are selected using the commonareas mask where low reflectivity zones are rejected but do not have low interferometric coherence (for more details, see Altamira Information, 2008).

\section{Comparing TerraSar-X images with the Spot-5 image}

By using the normalized deviation pond index (NDPI) obtained from Spot-5 optical remote sensing as defined by Lacaux et al. (2007), the contours of all ponds in a $40 \mathrm{~km} \times 40 \mathrm{~km}$ area clustered around the Barkedji village in the Ferlo zone, were precisely mapped. Free-water bodies were identification from six strip-map TerraSar-X 2008 images (27 July, 7 and 29 August, 9 and 20 September and 1 October). Then the six scenes were combined and superimposed onto the Spot-5 image (ENVI, version 4.3 software, ITT Visual Information Solutions; Boulder, CO, USA) during 26 August, 2003, which corresponds to maximum filling of all ponds in the same area to insure that free water bodies are indeed in the right location. In this way, the pond dynamics (filling-in and flushing-out) after significant rainfall events (obtained in real-time by the Tropical Rainfall Measuring Mission (TRMM) can be assessed properly. This ultimate check is to produce 
dynamical ZPOMs during the summer monsoon independently of adverse weather conditions.

The TRMM Microwave Imager (TMI) is a ninechannel passive microwave radiometer which builds on the heritage of the Special Sensor Microwave/Imager (SSM/I) instrument. The TRMM Precipitation Radar (PR) operates at $13.8 \mathrm{GHz}$, measures the 3-dimensianal (3-D) rainfall distribution over both land and ocean, and defines the depth of the precipitation layer. The TRMM algorithm combines data from both TMI and PR sensors to produce the best rainfall estimate. Since it has been shown by Vignolles et al. (2009) that the amount of water from a single rainfall event must reach at least $10 \mathrm{~mm}$ to produce a measurable effect (lower values do not affect pond dynamic significantly, if at all, resulting in no or very little vector production), only those events identified by TRMM were accepted in this study.

\section{Results}

When free-water bodies, detected by six images from TerraSAR-X in a strip-map mode (descending orbits (from July to October 2008), were superimposed on pond outlines obtained from the NDPI, computed using SPOT-Image data (Lacaux et al., 2007), the results were indeed encouraging. Not only was the large, single pond of Barkedji well filled-in, but individual and small ponds to the south could also be clearly identified (Fig. 3). More than $80 \%$ of free-water pixels obtained from TerraSAR-X fell within the outlines of all ponds at maximum fill identified by the Spot-5 image of 26 August 2003. In situ checking showed that the remaining 20\% free-water pixels constituted new ponds created during recent construction and roadwork.

From 1 June until 31 October 2008, 21 rain

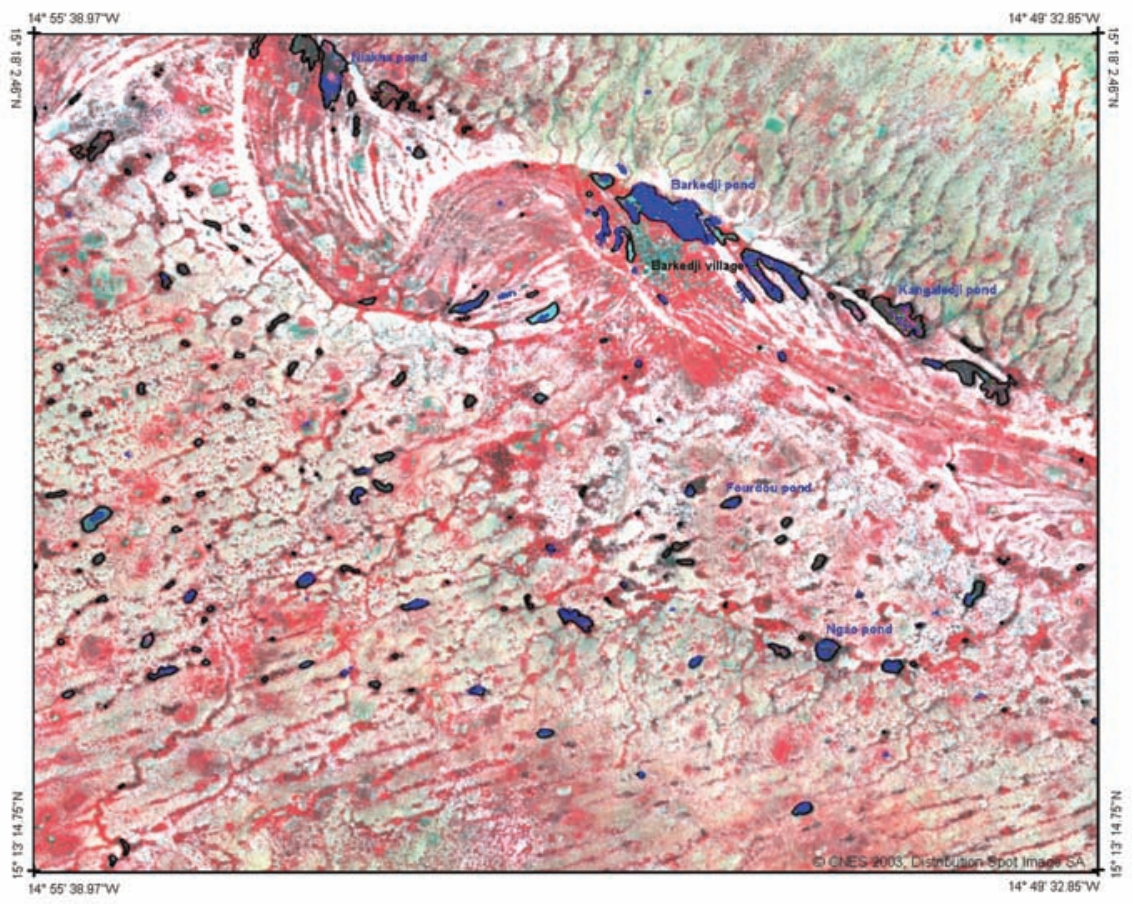

Fig. 3. New data obtained from TerraSAR-X radar monitoring of free-water bodies from six images during the 2008 summer monsoon compared with that obtained from Spot-5 image of 26 August, 2003, a point in time when all ponds were completely filled. Free-water pixels obtained from TerraSAR-X are in dark blue. The pond maximum footprints obtained from Spot-5 are outlined with black contour. The coordinates of the scene are given in each corner of the figure, whilst the names of the six ponds equipped with in situ limnimetry monitoring are spelled out. 
events (10 of which produced $10 \mathrm{~mm}$ or less of rainfall) were recorded by TRMM in the Barkedji area $(185,000$ ha). Serendipitously, out of these 21 rainfall events, three strong rainfalls $(47.6 \mathrm{~mm}$ on 20 July, $73 \mathrm{~mm}$ on 28 August, and $58 \mathrm{~mm}$ on 2 September) occurred just prior to the TerraSAR-X remote sensing, i.e. 27 July, 29 August and 9 September (Fig. 4). The rainfall events recorded here are representative of rainfall regimes over the Sahel, linked to squall-lines activity during the summer monsoon. Unfortunately, the programmed 18 August image is missing due to logistics, whilst the 7 August, 20 September and 1 October data were obtained after what, from an entomology perspective, are called "unproductive rainfall events". The free-water surfaces are expressed in ha and represent together approximately $0.1 \%$ of the entire area. Their high-resolution temporal variability permitted us to compute averaged pond coefficients in $\%$ as a function of rainfall amount. The daily mean flushing rate within the investigated area is thus of $3.3 \%$ of the total area (without any additional rainfall event) and consists essentially by evaporation, percolation and, to some degree, runoff. The variability of the pond areas (in \% on the $\mathrm{y}$ axis) as a function of rainfall events (in $\mathrm{mm}$ on the $\mathrm{x}$ axis) is given in Figure 5 for the six radar-monitoring periods. The mean pond dynamics within the Barkedji area can thus be obtained through natural logarithmic fitting during the analysed period according to the equation:

$$
y=18.51 \operatorname{Ln} x-29.11 \text { with } \mathrm{R}^{2}=0.97
$$

where $\mathrm{Ln}$ is the natural logarithm, and $\mathrm{R}^{2}$ is simply the square of the sample correlation coefficient between the observed and predicted values.

\section{Discussion}

It is shown here that high-resolution TerraSAR-X data can be used for accurate free-water body detec-

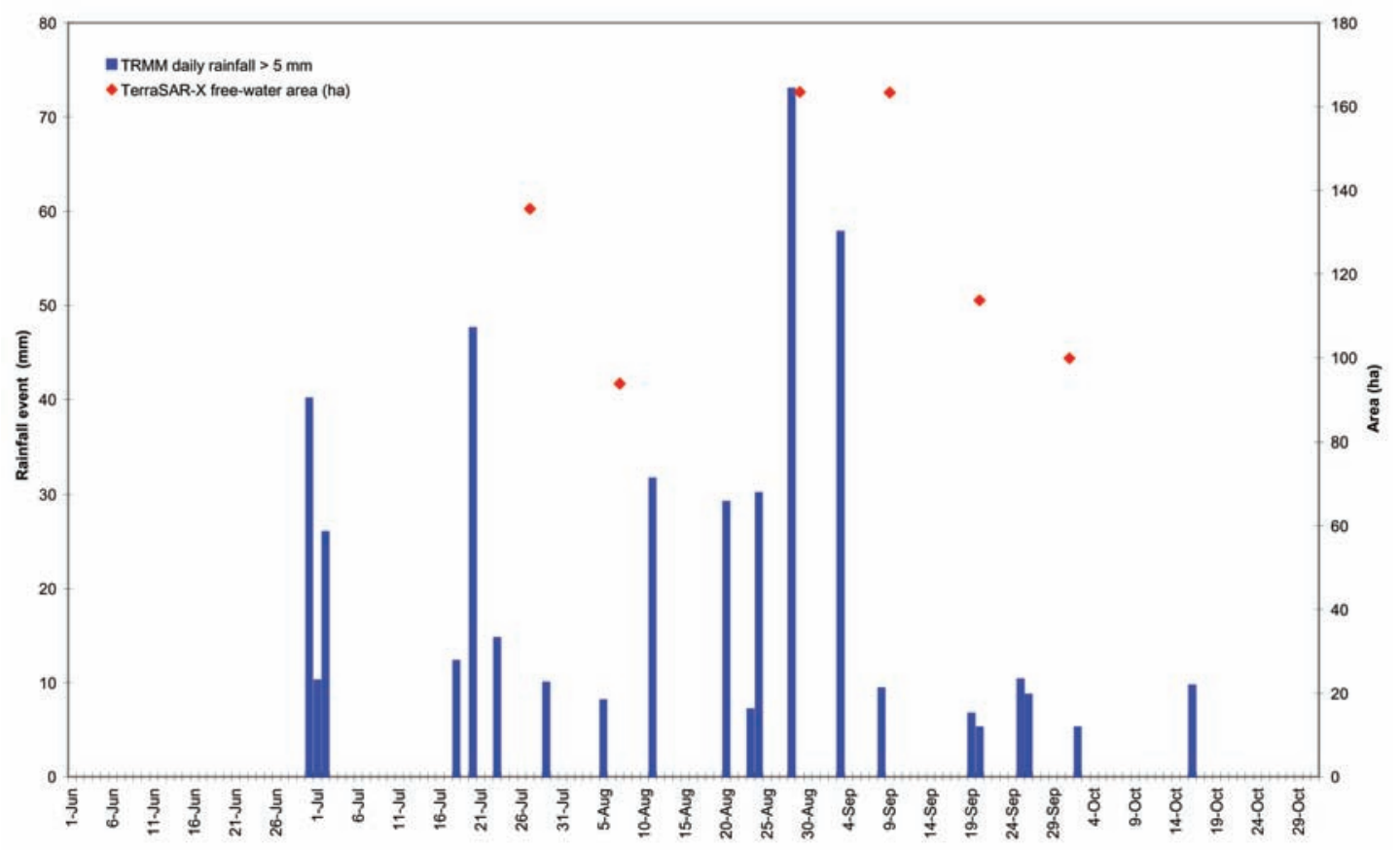

Fig. 4. TRMM rainfall events during the 2008 rainy season over the studied area (in mm) compared to the extent of free-water body obtained from TerraSAR-X (in ha). 


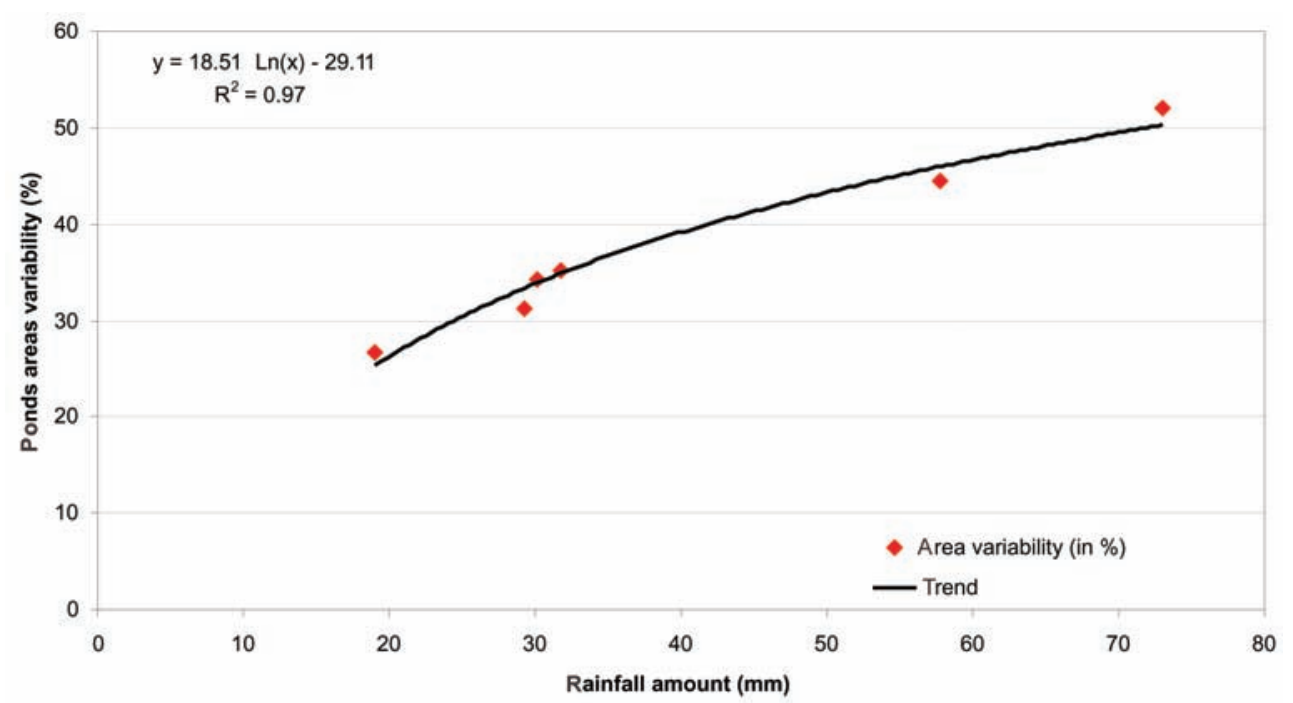

Fig. 5. Ponds area variability (in \%) as a function of rainfall events (in mm) within the studied area.

tion. Associated spatio-temporal monitoring of ponds and their dynamics can thus be assessed by an operational mode. This can be accomplished during adverse weather conditions, and particularly during the summer monsoon season in the study area when squalllines become active over the Barkedji area in the Ferlo region of Senegal, something which is not possible when using only Spot-5 imagery. Nevertheless, the latter data allowed for a definite and precise location of ponds (Fig. 3). Since pond dynamics are linked to vectors aggressiveness, ZPOMs and actual RVF risks can thus be mapped in quasi real-time.

Since recently, newsletters are distributed in a timely fashion and as many times as a productive rainfall event over the area is reported by TRMM. For example, the recent evolution of the dynamic ZPOM over the Barkedji area after the rainfall event of 13 July, 2010 (62.6 mm of rain) was reproduced in Figure 6 (see also Bulletin d'Information, 2010). Risks maps of the potential presence of Ae. vexans are thus distributed for the first time using radar technology and in quasi real-time to the AdaptFVR partners (Centre de Suivi de l'Environnement or CSE, and Direction des Services Véterinaires or DSV, Pasteur Institute) and stakeholders at large.
There is a need to implement programmes to predict and prevent RVF epidemics. Moreover since endemic cycle virus persists during dry season and interepizootic period through vertical transmission by Aedes mosquito infected eggs, it is hoped that the exact role of $C x$. poicilipes in the virus circulation during the course of the monsoon season will be evaluated in the near future.

In Senegal, RVFews are being implemented and used to generate risks maps and relevant dynamics after intense rainfall events. Through the AdaptFVR project, inter-disciplinary collaboration between different sectors (including meteorology, hydrology, ecology and entomology) is being improved. These new products are also meant to facilitate feedback exchanges between partners and to contribute to RVFews.

It is expected, from AdaptFVR and RVFews that gathered animals can be vaccinated and/or displaced rapidly on a coordinated fashion in regions were Aedes aggressiveness is foreseen as being relatively low. Vaccination could be the most practical way of preventing the disease in livestock in RVF-endemic areas. However, it has been recently shown that lifelong protective immunity is inadequate in cattle and 

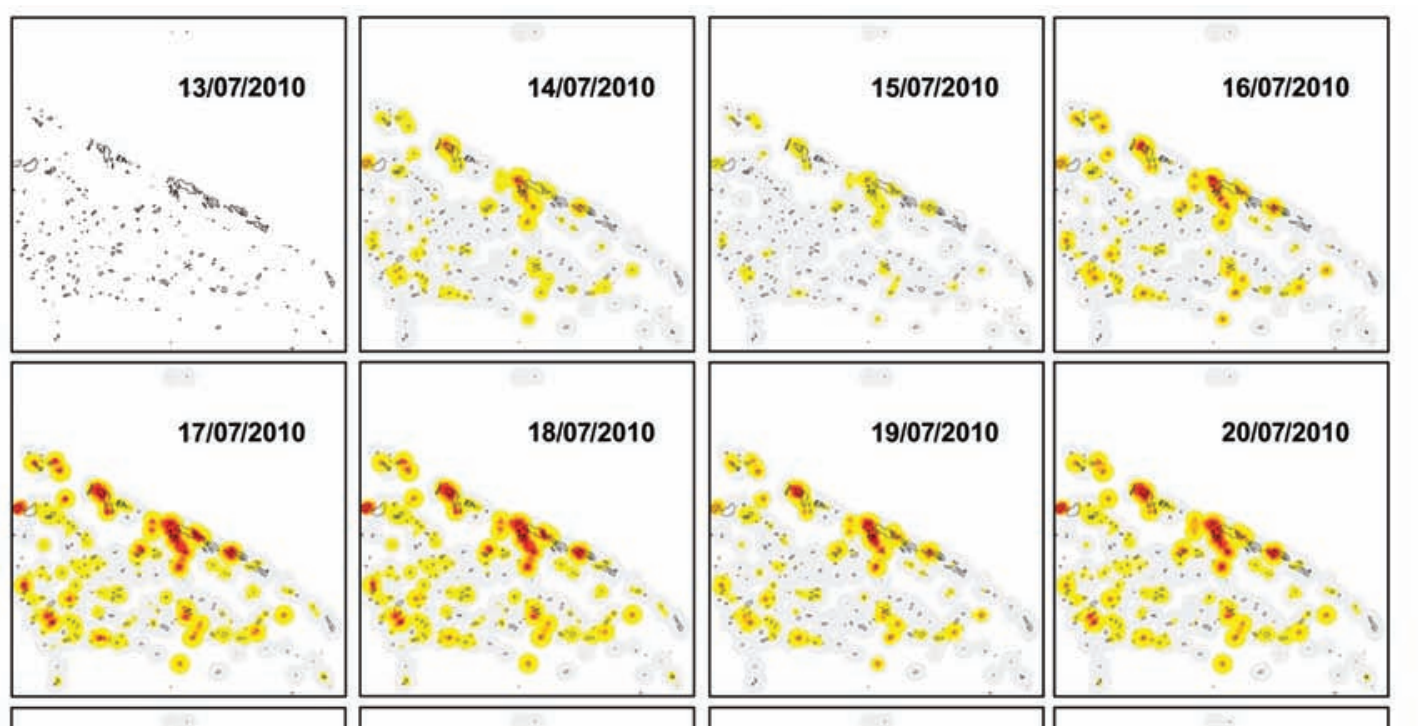

Hazard
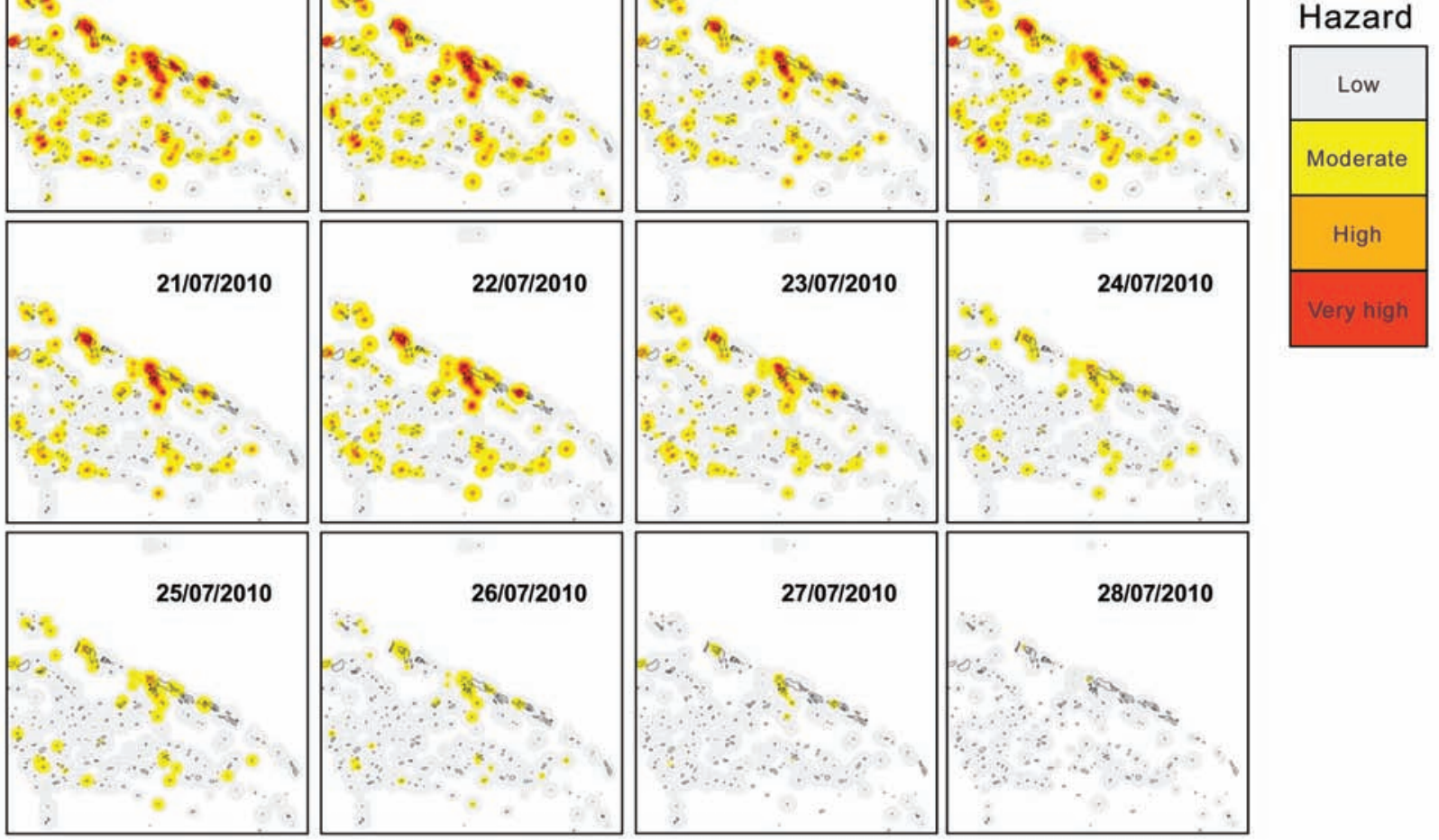

Fig. 6. Daily evolution of ZPOMs from 13 July (productive rainfall event of $62.6 \mathrm{~mm}$, observed by TRMM) to 28 July 2010, with ranked hazards for Aedes aggressiveness, from low level (in grey) to very high level (in red).

could cause safety problems such as reversion to virulence (Jansen van Vuren et al., 2010). Relocation of gathered animals identified from high-resolution, remotely sensed data (e.g. QuickBird of 0.6-4 m spatial resolution) is foreseen as a complementary means of prevention. Using TRMM and TerraSAR$\mathrm{X}$ data in real-time should thus mitigate the negative socio-economic impacts of RVF on the cattle industry and trades.

\section{Acknowledgements}

This study has been realized in the framework of the "AdaptFVR" project of the research program "Management and Impacts of Climate Change" or "Gestion et Impacts du Changement Climatique (GICC)" in French, managed by the Ministry of Ecology, Energy, Sustainable Development and Sea (Ministère de l'Ecologie, de 1_Energie, du Développement Durable et de la Mer, MEEDDM, in French). 
We thank the pioneers of tele-epidemiology, namely Drs. Antonio Güell and Jean-Pierre Lacaux, Director of Department of Applications and Valorizations at CNES, and Professor at Paul Sabatier University, respectively. Yves M. Tourre would also like to thank Drs Mike Purdy and Philippe Dandin, Directors of LDEO at Columbia University and DClim/MétéoFrance, respectively. This is LDEO contribution \# 7389.

\section{References}

Altamira Information, 2008. Epidemiology: ponds cartography and evolution using high resolution TerraSAR-X radar data. Barkedji Final Report, Ramonville SaintAgne, France, pp. 19.

Bâ Y, Diallo D, Dia I, Diallo M, 2006. Comportement trophique des vecteurs du virus de la fièvre de la Vallée du Rift au Sénégal: implications dans l'épidémiologie de la maladie. Bull Soc Pathol Exot 99, 283-289.

Bâ Y, Diallo D, Fadel Kebe CM, Dia I, Diallo M, 2005. Aspects of bio-ecology of two Rift Valley fever virus vectors in Senegal (West Africa): Aedes vexans and Culex poicilipes (Diptera: Culicidae). J Med Entomol 42, 739-750.

Bouloy M, Weber F, 2008. Molecular biology of Rift Valley fever virus. Open Virol J 7, 8-14.

Bulletin d'Information, 2010. Project AdaptFVR, Juillet, numéro 3. Laurent Imanache et Cécile Vignolles Editors. Sponsored by CNES, CSE, Institut Pasteur, DSV, MétéoFrance and NPO Reflets, France.

Jansen van Vuren P, Tiemessen CT, Paweska JT, 2010. Evaluation of a recombinant Rift Valley fever virus subunit nucleocapsid protein as an immunogen in mice and sheep. Open Vaccine J 13, 114-126.

Lacaux J-P, Tourre YM, Vignolles C, Ndione J-A, Lafaye M, 2007. Classification of ponds from high-spatial resolution remote sensing: application to Rift Valley fever epidemics in Senegal. Remote Sens Environ 106, 66-74.

Phong BT, 1975. Illumination for computer generated pictures. Communications of ACM 18 6, 311-317.

Tourre YM, Lacaux JP, Vignolles C, Ndione JA, Lafaye M, 2008. Mapping of zones potentially occupied by Aedes vexans and Culex poicilipes mosquitoes, the main vectors of Rift Valley fever in Senegal. Geospat Health 3, 69-79. Vignolles C, Lacaux JP, Tourre YM, Bigeard G, Ndione JA, Lafaye M, 2009. Rift Valley fever in a zone potentially occupied by Aedes vexans in Senegal: dynamics and risk mapping. Geospat Health 3, 211-220.

Zhang Y, Prinet V, 2004. InSAR coherence estimation. International Geoscience and Remote Sensing Symposium, Anchorage, AK, USA, 7 vol. (CVIII-4916 p.), IEEE International Symposium, 3353-3355. 